\title{
Intermédialités
}

Histoire et théorie des arts, des lettres et des techniques

Intermediality

History and Theory of the Arts, Literature and Technologies

\section{Missing Links: Digital Cinema, Analogical Archives, Film Historiography}

\section{Luca Giuliani et Sabrina Negri}

Numéro 18, automne 2011

archiver

archiving

URI : https://id.erudit.org/iderudit/1009074ar

DOI : https://doi.org/10.7202/1009074ar

Aller au sommaire du numéro

\section{Éditeur(s)}

Revue intermédialités (Presses de l’Université de Montréal)

ISSN

1705-8546 (imprimé)

1920-3136 (numérique)

Découvrir la revue

Citer cet article

Giuliani, L. \& Negri, S. (2011). Missing Links: Digital Cinema, Analogical Archives, Film Historiography. Intermédialités / Intermediality, (18), 71-84. https://doi.org/10.7202/1009074ar
Résumé de l'article

Le surgissement subit et envahissant des technologies numériques a fait l'objet de nombreuses études, de la part des chercheurs et des critiques de cinéma. Cependant, la plupart de ces études s'attachent surtout à l'impact des technologies numériques sur le film contemporain : sur sa production, sur sa distribution, sur sa diffusion, sur les produits qu'il génère. Dans la mesure où la production de films numériques est un point de rupture sans équivalent dans l'histoire, qui met en question la nature même du " film " et du " cinéma ", un risque surgit, à savoir que la numérisation des pellicules ait un effet irréversible sur l'histoire technologique du cinéma. Nous traitons de deux études de cas: la restauration en 1995 de la copie couleur du film de Jacques Tati de 1949, Jour de fête ; la découverte de quelques bobines de nitrate $16 \mathrm{~mm}$, dans une collection déposée au Museo Nazionale del Cinema de Turin, Italie. Ceci permet d'expliquer l'importance de la technologie pour l'historiographie du cinéma, et de réaffirmer la nécessité, pour les archives et les institutions académiques chargées de préserver la mémoire du cinéma pour les générations futures, de joindre leurs efforts. 


\title{
Missing Links: \\ Digital Cinema, Analogical Archives, Film Historiography*
}

\author{
Luca Giuliani, Sabrina Negri
}

n October 2011, an article titled "Film Fading to Black" was published in Creative Communities of the World, an online magazine aimed at media professionals. In contrast to a title banner depicting a classical looking statue of two angels, the article's rather shocking headline reads: "While the debate has raged over whether or not film is dead, ARRI, Panavision and Aaton have quietly ceased production of film cameras within the last year to focus exclusively on design and manufacture of digital cameras. That's right: someone, somewhere in the world is now holding the last film camera ever to roll off the line." ${ }^{\prime \prime}$ Although a large number of second-hand film cameras are still made available to professional filmmakers, the decision, on the part of three leading industrial manufacturers in the field, to discontinue production of new ones sends a strong signal. While the death of film has long been commented upon, the news of this further step towards its demise is nonetheless unsettling - within this context, the two angels on the above-mentioned banner set a rather gloomy, macabre tone.

It is not by chance that recent years have seen the reemergence of studies on film ontology. Although cinema has undergone a series of technological changes, few of them have had as strong an impact as its transformation into a

* This paper was first presented at the International Conference "The Impact of Technological Innovations on the Historiography and Theory of Cinema," organized by André Gaudreault (Université de Montréal) and Martin Lefebvre (Concordia University), Montréal, November 1-6, 2011.

1. Debra Kaufman, "Film Fading to Black," Creative COW: Creative Communities of the World Magazine, 2011, http://magazine.creativecow.net/article/film-fading-to-black (last access January 14, 2012). 
digital medium. While some scholars have decried the end of the cinema as we knew it-or, at least, of the idea of the cinema which was most prominent for over a century-, others have regarded the introduction of the digital as only another transitional moment within a larger cycle of film history. ${ }^{2}$ Either way, it is unquestionable that we are indeed facing a crucial breaking point where the very nature of "film" and "cinema" is at stake.

However, although this ongoing debate has been extremely lively in stressing, in turn, the instances of rupture and continuity between analog and digital cinema, it has focused mainly on the processes of contemporary film production, post-production, distribution, and their final products. Nonetheless, there remains another, less investigated, aspect of the debate which has major consequences for film historiography: the use of digital technologies for preservation purposes. As Giovanna Fossati explains in From Grain to Pixel:

There is very little theoretical work in the field of film and media studies with explicit reference to archives and archival practice. In a way, reading film and media literature one might think that the materiality of film, the significance of film as material artifact, has very little importance for theory, and that the objects of the scholars are not necessarily the same of the archivists. [...] In a theory of archival practice the film as artifact, in its different possible meanings, is central. In this work the term artifact is used in two different definitions, the material and the conceptual. The material film artifact is typically the film preserved by the archivist, whereas the conceptual film artifact refers to its abstraction as an historical and aesthetic object. ${ }^{3}$

The notion of film as an object is central to archival theories and practices. When we decide to digitally preserve the copy of an original which was initially conceived through analog means, what is left of the technological history of that

2. In the first group we might include, among others: Thomas Elsaesser, "The New Film History as Media Archaeology," Cinémas, vol. 14, n² 2-3, 2004; from another perspective, see also: Francesco Casetti, L'occhio del novecento. Cinema, esperienza, modernità, Milan, Bompiani, 2005 (English translation: Eye of the Century: Film, Experience, Modernity, New York, Columbia University Press, 2008). In fact, Casetti defines $21^{\text {st }}$ century cinema as Cinema due in opposition to the traditional Cinema uno, which was the "eye of the $20^{\text {th }}$ century" but no longer exists (p. 295 of the original edition). For examples of the other position, see, for instance: Giovanna Fossati, From Grain to Pixel: The Archival Life of Film in Transition, Amsterdam, Amsterdam University Press, 2009; Jonathan Rosenbaum, Goodbye Cinema, Hello Cinephilia: Film Culture in Transition, Chicago and London, University of Chicago Press, 2010.

3. Fossati, 2009, p. 104-105. 
specific piece of film? This question is urgent and needs to be addressed by both scholars and archivists alike.

Without a doubt, digital technology presents many advantages: it is cheaper ${ }^{4}$ and allows for easier and more flexible access to moving pictures. In addition, it opens up brand new technical landscapes to directors, cinematographers and, from another perspective, film restorers. On the other hand, cinema is rapidly moving toward the digital; a movement which will certainly have consequences, from both a practical and a theoretical standpoint. The dematerialization of the cinematic image forces us to reconsider the notion of film as an artifact and, therefore, the study of technological evolution as a critical and analytical tool. This shift in perspective has a definite impact, which remains to be explored and will undoubtedly affect the future of film studies.

There is a vast difference between the ontological status of a born-digital moving picture and an analog film which has been digitized subsequently. The former poses questions such as: "What has become of cinema today?" and "Can a digital moving picture still be considered cinema as we once knew it?" The latter, however, makes us wonder what the technological history of film might have in store for the future. Once digitized, it becomes virtually impossible to distinguish a Technicolor print from Ferraniacolor film stock; the technical shades of the past risk being flattened under a veil of pixels. While digitization poses other problems, such as the preservation of digital files and the standardization of formats ${ }^{5}$, we believe that this flattening is the main risk faced by archivists, both knowingly and unknowingly, when they take the decision to digitize a print.

The following discussion shall focus on the importance of the archive for film historiography and the dangers related to the mass digitization of analog artifacts. As archivists and restorers, our perspective is more pragmatic than theoretical; in some respects, it might be considered old-fashioned, even backward. In the present theoretical landscape, which is dominated by the concept of intermediality, film is

4. This assumption is, however, highly problematic. Digital film production and distribution are undoubtedly cheaper than traditional processes, especially because they reduce the costs of film printing and shipping to exhibition venues. On the other hand, digital technology becomes much more expensive if we take into consideration the preservation of digital files which need to be migrated at least once every five years to avoid corruption and to counter the obsolescence of their formats.

5. For a more pragmatic analysis of the consequences of the use of digital technology in film, see the Academy's Science and Technology Council's comprehensive report The Digital Dilemma, written in 2007 and downloadable from www.oscars.org/sciencetechnology/council/projects/digitaldilemma/ (last access January 16, 2012). 
considered just one medium of communication among others-such as television, computers or cell phones-with which it is increasingly connected. This process is made even more visible by the use of digital technology in the cinema. On the other hand, as film archivists, our everyday experiences remind us that film deserves to be treated as a technological form of expression per se, from the standpoints of both preservation and exhibition. This working hypothesis is essential to prevent cinema from turning into a "residual medium," akin to what Charles Acland has called a "living-dead' culture," in which an old medium, having been downgraded from the status of object of use to that of antiquity, is retrieved, reused, recycled, and brought back to life-often thanks to its interbreeding with new technologies. Some aspects of film culture as, for instance, home movies and small gauge films which are recycled by contemporary avant-garde artists, are already undergoing this process. However fascinating and fruitful it may be, it always also contributes to the falling into obsolescence of the very medium it seeks to revive. The purpose of a film archive lies, primarily, in keeping film alive and readily available for future generations. Thus, relinquishing the otherwise valuable concept of intermediality to the background of its argument, this article will aim to discuss the future of cinema and film per se, rather than situate it within the broader network of a multitude of media forms.

Following a direction first opened up by publications such as Cinéma $\&$ Cie and Film History - each of which has dedicated a special issue to the topic under discussion-and the work of scholars such as Michel Chion, Tom Gunning and David N. Rodowick, to cite but a few, we will reassert the irreplaceable importance of film technology within the field of cinema studies. Crucially, it is within this very moment of transition that we have identified two missing links between digital cinema, analog archives and film historiography. The first missing link is the object; the second is technology. Through an analysis of these missing links, we will outline the potential risks of digitization, and suggest possible courses of action for avoiding or sidestepping these risks.

\section{MISSING LINKS: THE OBJECT}

In 1955, Éric Rohmer wrote his famous essay "Le celluloïd et le marbre," which was published in the Cahiers du Cinéma. There, he argues that cinema is undoubtedly a form of art because, in addition to being a tale in the form of images, a film is also an object that can be touched in exactly the same way as

6. Charles R. Acland (ed.), Residual Media, Minneapolis and London, University of Missesota Press, 2007, p. xx. 
a painting or a sculpture. Due to its plastic-like quality, which appeared resistant to decay, Rohmer thought that celluloid could be preserved to the point of outlasting marble, and that it would serve to document the history of the world and of cinema itself:

$\mathrm{Si}$, par quelque cataclysme, notre civilisation disparaît tout entière, on peut aimer penser qu'un film précautionneusement enfoui sous terre en restera, pour les âges à venir, le plus fidèle témoin. ${ }^{7}$

As we well know, unfortunately, Rohmer was wrong about the survival of celluloid, whose life expectancy, in most cases, rarely exceeds one hundred years. Rohmer, of course, is not to be blamed for his idealistic positions. Aesthetics and historiography have always been nourished with utopian ideals, which find their raison d'être within their own cultural environments. Instead, it would be more useful to speak of a missing link between, on the one hand, an idealistic view of film history and, on the other, film's material nature. In fact, although cinema's foundational mythology depicts it as a form of art based on and dependent upon technology, the consequences of this principle have often been neglected. Rohmer's article, whose primary purpose is to define cinema's specificity in comparison with other forms of art, is emblematic of this gap: at that time, film archives had been around for over twenty years and the problems of film preservation were already being widely discussed. However, outside of the archival field, the problem was rarely taken into consideration.

The situation has not changed much since Rohmer's time. Although film archive research has lost some of its "ivory tower" halo and has long opened its doors to film scholars by providing them with fresh tools to shed new light on film history, ${ }^{9}$ very little theoretical work has been done on film as an object. The main reason for this situation, in Giovanna Fossati's words, lies in the confusion between the "material film artifact" and the "conceptual film artifact." More precisely, the confusion resides in the definite predominance of the latter; the bigger the distance between these two concepts, the higher the risk of moving away from the material nature of cinema, reducing film to a series of moving images

7. Éric Rohmer, Le celluloïd et le marbre suivi d'un entretien inédit, Paris, Éditions Léo Scheer, 2010 (originally published in the Cahiers du Cinéma, ${ }^{\circ} 44,49,51,52,53,1955$ ).

8. This definition was first coined by Patrick Loughney, Chief of the National AudioVisual Conservation Center at the Library of Congress.

9. The revival of interest in early cinema, fostered by the famous 1978 FIAF (Fédération Internationale des Archives du Film) conference, held in Brighton with the participation of archivists and scholars, is a perfect example of this. 
with no consideration for the medium's physical specificity instead. Although cinema has always been considered a mechanically reproducible medium, a certain amount of loss or alteration at every step of the duplication process is unavoidable; this is why film's material status must always be kept in mind, in order not to reduce it to its so-called "content." Needless to say, technology risks becoming the tombstone on the material particularity of every copy.

Films as objects are irreplaceable testimonies of film history. A recent discovery made at the Film Archive of the Museo Nazionale del Cinema in Torino ${ }^{10}$ illustrates this point. In one of the collections of the Museo, we found a considerable number of $16 \mathrm{~mm}$ nitrate films among thousands of safety (acetate and polyester) elements. This discovery might seem of little importance to someone unfamiliar with archival practices. Yet the discovery of these materials has crucial historiographic consequences, as $16 \mathrm{~mm}$ films were believed to have been manufactured exclusively on safety stock. ${ }^{11}$ Their very existence, in addition to being of significance to daily archival practices, ${ }^{12}$ reshapes a large part of cinema's industrial history. Through the analysis of films and film-related materials, we were able to identify the manufacturing dates of these elements and to account for the move away from mainstream industrial practices. This research also led to a redefinition of small gauge distribution strategies in the 1940s and 1950s,

10. See Sabrina Negri, Luca Giuliani: "Do You Have Any 16mm Nitrate Films in Your Archive? The Case of Ferrania 16mm Nitrates in the San Paolo Film Collection at the Museo Nazionale del Cinema in Torino," FIAF Journal of Film Preservation, vol. 84, $\mathrm{n}^{\circ} 4,2011$.

11. See, among others: "Identifying and Handling Nitrate Film," the Association of Moving Image Archivists's Guidelines, available on the AMIA web page at www.amianet. org/groups/committees/nitrate/documents/NitrateIGNovo8.pdf (last access January 14, 2012); Glenn E. Matthews and Raife G. Tarkington, "Early History of Amateur MotionPicture Film," The Journal of the Society of Motion Picture and Television Engineers, vol. 64, March 1955; Paul Read and Mark Paul Mayer, Restoration of Motion Picture Film, Oxford, Butterworth-Heinemann, 200o; Roger Smither (ed.), This Film Is Dangerous: A Celebration of Nitrate Film, Brussels, FIAF, 2002.

12. Unlike acetate and polyester, nitrate is highly flammable. The possibility that there were nitrate elements among safety elements required us to re-inspect the entire collection in order to track down other $16 \mathrm{~mm}$ nitrate films not recognized by previous inspectors; these had to be moved to the safer nitrate vault. Other archives conserving similar collections might need to reevaluate their holdings in the same way; they will need to be more careful in the presence of $16 \mathrm{~mm}$ film stock because, despite what we have learned from books, these films could, in fact, have nitrate elements. 
revealing a previously hidden Italian-American connection and, as a result, new aspects of the history of cinema in both countries.

If we had only paid attention to the content of these films, which contain popular moving pictures and are available in plenty of formats, both analog and digital, we would have missed their historical importance. Their specificity and uniqueness reside in the material nature of the film object itself. In order to conduct our study, the analysis of film artifacts was key: without observing the position of splices, the style of edge codes, the type of film stock, and the correspondence between duplicate negatives and film prints, it would have been impossible to begin the process of historiographic research. In addition to telling a tale through images, film is an object. As the above-outlined example highlights, this fact must be taken into account when we study and write film history.

\section{MISSING LINKS: TECHNOLOGY/TECHNOLOGIES}

Since film objects might be considered missing links between archival practices and historiographic theories, film technology can be viewed as the unaccounted for connection between moving pictures and film history and criticism. Of course, the material nature of film is crucial to the study of technology as well. Although the two-color Kodachrome and the two-color Technicolor systems might appear similar on screen, they have very different technological histories with radically opposed commercial outcomes; at the same time, although the Ferraniacolor and the Eastman color systems share the same technological concept, they definitely cannot be confused once they are projected. On the other hand, the same technology can be used in a variety of ways by different directors or cinematographers. Thus, it might be difficult to believe that both Senso (Luchino Visconti, 1954) and The Tales of Hoffmann (Michael Powell and Emeric Pressburger, 1952) were shot with the same Technicolor system. Technology and style, then, are inextricably intertwined and, consequently, the study of one of these aspects can shed light on the other.

Of course, it would be a gross oversimplification to affirm that technology has never been taken into consideration in film studies. Much to the contrary, its analysis has been crucial to the development of film theory since the 1970s. However, in 1970s film theory, technological aspects were mostly taken into account as being related to the ideological framework which underlies the cinematic form. As a result, and with the replacement of the historical-materialistic model by the so-called "crisis model," historiographical frameworks tend to analyze only major industrial realities, which ultimately participate in the very evolutionary and deterministic interpretation of film history they wish to counter. 
While the crisis model shows how a new technology emerges through a threestep identity crisis (multiple identification, jurisdictional conflict, and over-determined solutions) ${ }^{13}$ which provides an extremely effective way of describing the development of cinema's industrial system, that same model proves unconvincing when applied to non-Hollywood realities, like that of European film production. This problem is well represented in studies on color and sound in film. ${ }^{14}$ While the story of Technicolor has been told dozens of times, how many historical accounts have been made of minor and mostly forgotten color systems, especially when these were invented outside of Hollywood's industrial machine?

A new model is needed to deal with systems based on craftsmanship rather than industrial models, as was the case in Europe for most of its cinematic history. The study of technology is insufficient; instead, it would be more appropriate to speak of a study of technologies, which would not only include successful inventions, but also technological digressions from the so-called "norm", thus further questioning the supposed linearity of film history. Technological delays, commercially unsuccessful patents, recoveries of obsolete techniques, rediscoveries of technologies from the past-these are all aspects which are crucial to a deeper understanding of moving pictures and their history. However productive it may be, this approach also bears a number of risks: thus, one might be tempted to indulge in a nostalgic attitude, reducing evidence from the technological past to a series of oddities and memorabilia without considering its historical relevance and influence. As Timothy Druckrey points out in his foreword to Siegfried Zielinski's book Deep Time of the Media:

The mere rediscovery of the forgotten, the establishment of oddball paleontologies, of idiosyncratic genealogies, uncertain lineages, the excavation of antique technologies or images, the account of erratic technical developments, are, in themselves, insufficient to the building of a coherent discursive methodology. [...] The rediscovery of uncommon or singular apparatuses, novel and fantastic as they might be, is neither decisive nor fully adequate to formulate an inclusive approach that distinguishes it from connoisseurship, or worse, antiquarianism. [...] Media archaeology faces numerous issues: to evolve history of technologies, apparatuses, effects,

13. Rick Altman, Silent Film Sound, New York, Columbia University Press, 2004, p. $15-17$.

14. See, among others: Douglas Gomery, "The Coming of the Talkies: Invention, Innovation and Diffusion," in Tino Balio (ed.), The American Film Industry, Madison and London, The University of Wisconsin Press, 1976, p. 193-211. 
images, iconographies, and so forth, within a larger scheme of reintegration in order to expand a largely ignored aspect of conventional history. ${ }^{15}$

Zielinski then elaborates further in the book:

The goal is to uncover dynamic moments in the media-archaeological record that abound and revel in heterogeneity and, in this way, to enter into a relationship of tension with various present-day moments, relativize them, and render them more decisive. ${ }^{16}$

Thus, it is essential to consider film artifacts to be full primary sources when dealing with the issue of technology. As we pointed out earlier, we would be able to distinguish a two-color Kodachrome film from a two-color Technicolor one simply by looking at film prints; it would, however, be very hard to tell them apart just by watching them projected. ${ }^{17}$

A very good example of the strong link between artifacts, technology and style is provided by the 1995 restoration of Jacques Tati's Jour de fête, carried out by François Ede and Sophie Tatischeff. ${ }^{18}$ The production history of Jour de fête is a very peculiar one indeed: the film was shot in 1949 with two adjacent cameras, one which was recording on standard black and white stock, and another set up to shoot on a color stock called Thomsoncolor. Thomsoncolor was a lenticular color system, based on the same patent as Kodak's 1928 Kodacolor.

The functioning of the lenticular color system was very complicated: thousands of small, cylindrical lenses were embossed on the base of black and white panchromatic film stock, which was exposed through a three-color filter in a special camera. Each tiny lens would split the light beam passing through the filter into three segments while, on the emulsion side, it recorded variations in density according to input color value. During projection, the same three-color filter used for shooting reconstructed the color image on-screen. Basically, the

15. Timothy Druckrey, foreword to Siegfried Zielinski, Deep Time of the Media: Toward an Archaeology of Hearing and Seeing by Technical Means, Cambridge (Mass.), MIT Press, 2006, p. Ix.

16. Zielinski, 2006, p. 11.

17. Furthermore, due to their physical conditions, and to laws prohibiting the projection of nitrate films in most countries, it would be virtually impossible to screen either a two-color Kodachrome or a two-strip Technicolor original print.

18. See Vincent Ostria, "Entretien avec François Ede et Sophie Tatischeff," Cahiers du Cinéma, n 487, January 1995; Lisa Nesselson, "Jour de fête," Variety, January 9, 1995; François Ede, "Jour de fête: I colori ritrovati," in Giorgio Placerani and Fabiano Rosso (eds.), Il gesto sonoro. Il cinema di Jacques Tati, Milan, Il Castoro, 2002, p. 57-68. 
tiny lenses and the three-color filter were used to deconstruct the color image during the shooting process and to reconstruct it during projection; thanks to this system, a color image could be recorded onto black and white film stock.

While lenticular color systems were fascinating, various problems led to their commercial failure. First of all, the system required a special projector which limited its marketability. At the same time, it was very difficult to produce the number of prints necessary for widespread distribution. Not surprisingly, the Kodak Company designed the Kodacolor for the amateur market, for which it manufactured only $16 \mathrm{~mm}$ lenticular film. In addition, although the quality of colors was very high, the projected image appeared quite dark because of the three-stripe filter's position behind the lens.

Not even one color print of Jour de fête was produced in 1949. Because of technical and financial difficulties, the film was released in an 88-minute black and white version in 1949, before being re-released in 1961 in a stencil colored version with some added scenes. Nonetheless, Tati kept the original color negative, with the hope of one day showing his film the way it had originally been conceived. The hope was realized in January 1995, when Jour de fête's color restoration was screened to celebrate the centennial of the birth of cinema. Painstaking restoration work had started in 1987 and, thanks to meticulous historical and technological research, the technical and stylistic complexities of Tati's film were made available to audiences.

However, this tremendous effort had wider historiographic consequences - extending beyond the mere presentation of the 1949 version of Jour de fête. Unfailingly, a scrupulous restoration ends up broadening the scope of its endeavor to include not only the film in question, but the entire oeuvre of its authors, as well as the historical, technological and economic landscape in which they operated. In this case, it would have been impossible to carry out the restoration without an in-depth investigation of the Thomsoncolor system, both from a technological and from a historical standpoint. In order to recreate the colors that Tati had in mind, it was necessary to carefully inspect the original negative and to study the mechanics of the Thomsoncolor camera; at the same time, it was impossible to avoid the questions raised by Tati's choice of such an obsolete and complicated color system. The research conducted around Jour de fête allowed for a deeper understanding of Tati's style and provided a new perspective on European film history. It also revealed a previously hidden commercial and ideological agenda, tied to the quest for a European color film which would provide an alternative to the ever-present American Technicolor 
system. ${ }^{19}$ Tati's film, as both a material and a conceptual artifact, gave researchers with the tools necessary to investigate lesser known aspects of film history, providing a more complex and comprehensive view. Without the analysis of physical objects and technological details, this vantage point would not have been accessed.

\section{ANALOG PAST, Digital fUtURE: A PROBLEMATIC TRANSITION}

We believe that the two above-cited examples of the retrieval of $16 \mathrm{~mm}$ nitrate films and the restoration of Jacques Tati's Jour de fête exemplify the importance of material artifacts and technologies in film historiography. Objects are irreplaceable for the study of technology and we cannot do without technology when we study film history. At this juncture, it becomes necessary to situate digital tools along a theoretical spectrum where even small technological details make a great difference in the unfolding of cinema history. Again, we are considering the digitization of analog films rather than the production of moving pictures in digital formats. These two operations raise different problems, though they are strongly related in certain respects, such as preservation and production. It must also be noted that some issues relating to the digital transfer of analog films will likely affect the preservation of born-digital moving pictures as well.

We typically speak about the digital as if it were a homogeneous technology without any distinctions, an undifferentiated mare magnum of pixels which stands in stark contrast to the variety of technological hues of analog cinema. This is not completely true. Digital cinema has many different formats and standards whose specificities remain largely unacknowledged by film critics and theorists. The situation is no different in film archives, where the choice of which format to use when transferring a film print to a digital carrier is hardly an easy one. The heterogeneity of digital technology must be taken into account from both a theoretical and a practical level if we want to avoid repeating mistakes made in regard to film technology in the past. ${ }^{20}$ The wider implications of this question

19. See Luca Giuliani, "I colori di Jour de fête: fra anticipazioni stilistiche e ritardi tecnologici," in Placerani and Rosso, 2002, p. 69-79; for an account of Italian participation in the quest for a European color system, see: Luca Giuliani, "Una volta si scriveva così: Ferrania," in Vincenzo Buccheri and Luca Malavasi (eds.), La materia dei sogni. L'impresa cinematografica in Italia, Rome, Carocci, 2005.

20. Consider, for instance, the duplication of tinted and toned silent films on black and white film stock or the transformation of the aspect ratio of films transferred to electronic formats to accomodate the image size to TV screens. 
are far too great to be dealt with in the space allotted here; therefore, and keeping in mind the risks related to a simplistic understanding of digital technology, the remainder of our analysis will focus on the digital transfer of analog artifacts and the potential challenges of such an operation.

The risks connected to a massive and unproblematic digitization campaign are very serious indeed, particularly if we consider that films are preserved not only for today's audiences and scholars, but especially for generations to come. How will future historians be able to distinguish between different film technologies two, three or five hundred years from today, if all the artifacts remaining have been digitized? What will become of the technological specificity of a moving picture when it is converted into pixels? This problem needs to be addressed now, while material objects are still available to archivists and historiographers.

It must also be said, however, that digital technology is only one side of the problem: it radicalizes an issue intrinsic to the cinema as a medium which is only partially mechanically reproducible. No film print is identical to another. A polyester Eastmancolor print is radically different from a nitrate Technicolor of the same moving picture, although they are both analog carriers. Some elements, such as the film stock or the chemical composition of the emulsion, cannot be duplicated. Besides, even when two films are printed on the same stock with the same kind of emulsion, the passing of time will have different effects. The selection of a particular print to be duplicated for preservation purposes is often all but intuitive and, whatever decision is made, the preservation copy will always be different from the source. As outlined above, this problem becomes even more serious if a digital file is to be the final output of the restoration process. The result of the transfer would be different in nature from the print source, inevitably influencing, among other things, the viewing experience itself. Without a doubt, the preserved film would be very different from the one that was projected for the first time; thus, it is probably too early to tell whether such processes, and the results they garner, even fall under the definitional category of "cinema" at all. ${ }^{21}$

We often hear that the future of cinema is digital. In fact, this statement is inaccurate: the digital is already the present of the cinema, as long as we assume

21. As Rick Altman points out, when television was introduced as a new technology, most people continued to call it "radio" because they did not have the same perception of television we have. Calling the new medium by a new name was thus a fundamental step towards its cultural appropriation. It would not be surprising if a similar process occured with respect to digital cinema. See Altman, 2004, p. 15-16. 
that this appellation is still adequate to designate the electronic images we see projected on screens by way of a continuous stream of information. If, indeed, film cameras are no longer being produced, isn't film stock next? Moving pictures will be shot exclusively with digital cameras and analog films will only be preserved digitally. While the potential theoretical consequences of the first fact are already being partially discussed by film theorists and historians, it seems that the second set of issues is being taken into consideration within archivists and restorationist circles only. As we sought to make visible, archivists and scholars need to join efforts to preserve the memory of cinema in all its different aspects. If we do not intervene now, we run the risk of jeopardizing the possibility of a true understanding of film history on the part of future scholars, while also denying future audiences the possibility of a full cinematic experience.

Naturally, the course of events cannot be altered; the film industry has made a fast and definite turn toward the digital, inevitably ushering in a transition process for those archival institutions and exhibition venues that ultimately depend upon it. Radically reactionary positions can only delay, if not deny, the possibility of shared knowledge and understanding of the issue. It is necessary to acknowledge this state of affairs and start thinking of possible strategies to address the problem.

On the archival side, as obvious as it may sound, film and film-related artifacts must be conserved for as long as their physical conditions will allow. Unfortunately, we are getting closer and closer to the day when all nitrate and acetate films will have decomposed, leaving behind only later-generation analog or digital duplicates. Before this happens, it is crucial that film archivists and restorers thoroughly document their work, in order to record the technological and physical specificity of the films they have been working on.

On the other hand, the passive preservation of artifacts is not enough. Indeed, there is little point in storing materials if nobody ever looks at them. This is a major problem in archives, where lack of funding and shortages of staff often prevent the careful and regular inspection of collections. Thereby, the opportunity to grasp a real understanding of the historical testimonies offered by the materials themselves and the history of cinema at large is undermined. This is another reason why joint efforts are crucial, despite practical hardships. The archival and the academic worlds have long been estranged, almost mutually exclusive. We believe they need each other; especially in moments of transition like the one we are currently expenencing.

Film historiographers and theorists should broaden the scope of their analyses by considering the importance of material, as well as conceptual, artifacts. 
In addition to helping preserve the memory of lesser-known moments within the history of cinema, this will allow historiography to further challenge the linear development of film history by taking into consideration alternatives to mainstream positions and practices. Thanks to the work of archivists, restorers and scholars who laid the ground for the development of a more comprehensive methodology, one that seeks to integrate archival and scholarly work to prevent the disappearance and antiquation of historical artifacts, a door has been opened. To ensure that future scholars have the tools to study film history in the best possible way, and to prevent them from forming distorted views of this historydue to inaccurate documentation, incomplete historiography and the disappearance of material artifacts - it is necessary to widen this opening even further and pursue the paths it offers. 